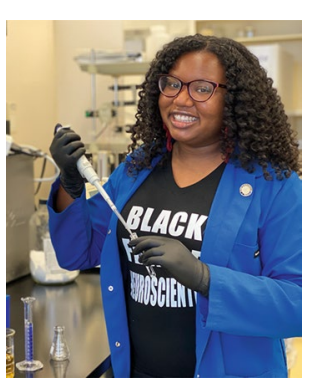

\title{
How to better support Black trainees in the biomedical sciences
}

\author{
The relentless violence against Black people takes an overwhelming emotional toll on \\ Black trainees. In those we continue to lose, we see our families, our friends and our own \\ lives being taken.
}

n June 2020, amidst the worldwide protests about the murders of George Floyd, Breonna Taylor, Ahmaud Arbery and countless others who were the victims of police brutality and white supremacy, I was lost and exhausted. I had been working on advancing to candidacy for my doctoral degree, but I was drowning in the repetitive videos of Black bodies being brutalized. I was struggling to juggle my research with the fear of losing loved ones to COVID-19, a constant fight against microaggressions and stereotypes, and the greater fear of our lives being taken for simply existing while Black.

Since the vast majority of scientific researchers in the USA are non-Black, it can be daunting to express how these events impact my mental health and my ability to be 'productive.' Not wanting to confirm the imposter syndrome that I battle regularly as a first-generation college graduate, I was very hesitant to tell my PI about the unique challenges I was facing. When I finally worked up the courage to talk to her, I was grateful that she was incredibly receptive and offered support in every way possible. But not every Black trainee is so lucky.

As a PI and mentor, your reactions about these events can dictate whether your trainees ever feel safe to speak up again. Before we are scientists, we are people. Our self-advocacy requires an immense amount of bravery. It is consuming, is psychologically draining and could cause future troubles for us. So, not every underrepresented person wants to confront all instances of racism head-on. But with the perpetual anti-Black violence still occurring, I want to give a few suggestions for mentors to better support their Black trainees.

Make it very clear that you are an ally. Don't wait for us to start the conversation, because your silence speaks volumes. Let it be known if your office is a safe space. Host quarterly lab meetings that are focused on efforts the lab is making to become anti-racist and on current issues affecting diverse students. Critically think about the ways in which your research impacts minority and low-income communities. Call out your colleagues on their racism.
Educate yourself. Become aware of the systemic hurdles that every Black student has had to overcome to get to this point. Black Americans hold 2\% of the national wealth, which means less access to private schooling, tutors and prep programs. Standardized tests have been shown to be biased against minority students and those belonging to a lower socioeconomic status. Almost half of Black students enrolled in a postsecondary institution are first-generation college students, which means they may not know about as many scholarship or internship opportunities as their peers do. This isn't even addressing the racial profiling, subpar medical care and over-policing that takes a physiological toll. Take these into consideration when considering graduate school applicants and hiring. Furthermore, actively encourage applicants from nationally funded diversity initiatives that uplift Black students in the biomedical sciences, such as Maximizing Access to Research Careers, and Diversity Specialized Predoctoral to Postdoctoral Advancement in Neuroscience.

Speak up for your Black trainees. Advocate for us when we're not in the room. Nominate us for awards and speak highly of our efforts. Let us know about fellowships, travel grants and other opportunities that can help advance our careers. Teach us how academia works and the 'unspoken' etiquette in the field.

Use your position of power to be a champion for equality and racial justice. You do not have to belong to an underrepresented group to support the people in that group. Demand that your departments and schools hire diversity and inclusion experts to host implicit-bias workshops and cultural-competency trainings. When they do want to hear from the current Black student and faculty perspective, find ways to compensate them for this diversity work. But also recognize that the one Black student cannot speak for all Black people. Black experiences are not a monolith.

Ensure Black leaders in your field are invited to give research talks at conferences, symposia and departmental seminar series. Encourage everyone to attend, not just the underrepresented students, because perceptions and stereotypes can be changed all around.

If you do not identify as the same gender, race or background as your trainee, help them find a mentor who does. My advisor and I have a mutual understanding of sexism in science. But as a white woman, she cannot fully understand how racism is compounded in my experience. One of the best things she did was to connect me with another Black neuroscientist and professor. Although he is across the country, I appreciate being able to discuss being a Black person in the field without explaining the underlying nuances of my experiences. Having both of them as mentors can help me navigate multiple intersections of my academic identity.

Recently, I and other neuroscientists worldwide created an initiative with the goals of celebrating Black excellence in neuro-related fields, building community and helping young Black scholars find mentors. At BlackInNeuro.com, we have an ever-expanding list of fellowships and other helpful resources, as well as profiles of Black people in these fields at all levels who are willing to serve as mentors. This is a valuable connection for your Black trainees.

This is not an exhaustive list of all the things you can do. But it is a start. As a Black woman in neuroscience, I can inspire Black students to see themselves in science. I can help guide them to overcome seemingly insurmountable obstacles. But I cannot do it alone. We need non-Black allies to support, encourage and help mentor Black students in the best ways possible. Everyone can do something to make a difference. But don't just do it now when the world is watching do it always.

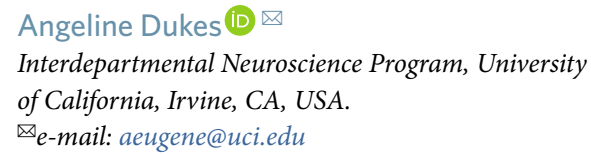

Published online: 15 October 2020 https://doi.org/10.1038/s41591-020-1101-3

The author declares no competing interests. 